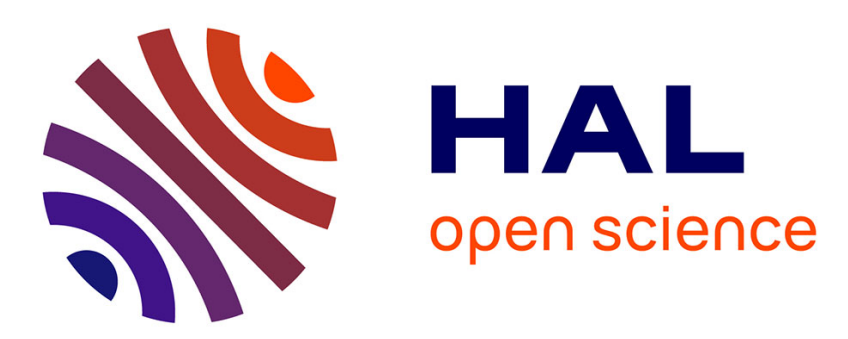

\title{
Process Modification for Improved Low Temperature CMOS Performance
}

\author{
C. Hwang, C. Jenq, B. Hammond, J. Gillick, J. Woo
}

\section{To cite this version:}

C. Hwang, C. Jenq, B. Hammond, J. Gillick, J. Woo. Process Modification for Improved Low Temperature CMOS Performance. Journal de Physique IV Proceedings, 1996, 06 (C3), pp.C3-193-C3-197. 10.1051/jp4:1996329 . jpa-00254247

\section{HAL Id: jpa-00254247 https://hal.science/jpa-00254247}

Submitted on 1 Jan 1996

HAL is a multi-disciplinary open access archive for the deposit and dissemination of scientific research documents, whether they are published or not. The documents may come from teaching and research institutions in France or abroad, or from public or private research centers.
L'archive ouverte pluridisciplinaire HAL, est destinée au dépôt et à la diffusion de documents scientifiques de niveau recherche, publiés ou non, émanant des établissements d'enseignement et de recherche français ou étrangers, des laboratoires publics ou privés. 


\title{
Process Modification for Improved Low Temperature CMOS Performance
}

\author{
C. Hwang, C. Jenq*, B. Hammond*, J. Gillick and J. Woo
}

Department of Electrical Engineering, University of California, Los Angeles, 405 Hilgard Avenue, Los Angeles, CA 90095-1594, U.S.A.

* Superconductor Technologies Incorporated, 460 Ward Street, Suite F, Santa Barbara, CA $93111-2310$,

U.S.A.

\begin{abstract}
Only minimal performance improvement is achievable when a standard, room-temperature CMOS component is cooled down to low temperatures. However, by modifying the process flow, a $2-3 \mathrm{x}$ increase in performance is possible. TCAD tools can be used to study and optimize an original, room temperature CMOS process for low temperature operation. By adjusting the low temperature threshold voltage to a room temperature value, CMOS ring oscillator delays drop in half. Even greater improvement is possible if a lower threshold voltage is used.
\end{abstract}

\section{INTRODUCTION}

Low temperature CMOS has attracted considerable interest in recent years due to its many improvements in device performance, including higher carrier mobility, increased current drive, and lower subthreshold slope. In designing and optimizing CMOS for low temperature operation, new structures and guidelines different from and unrelated to standard room temperature approaches have been proposed $[1,2]$. Modification of an already existing room temperature process may be a more practical, costeffective way to implement a low temperature CMOS technology. In addition, the impact of adjusting certain process steps for improved low temperature performance can be better understood and quantified. In this paper, improvements in low temperature CMOS performance will be studied through changing a conventional $1 \mu \mathrm{m}$ room temperature CMOS process.

\section{PERFORMANCE LIMITATIONS OF ROOM TEMPERATURE CMOS}

Cooling down a room temperature technology only enhances performance to a small degree. Figure 1 shows the linear $\mathrm{I}_{\mathrm{ds}}-\mathrm{V}_{\mathrm{gs}}$ characteristics of a $25 \times 25 \mu \mathrm{m}$ NMOS device at different temperatures. Higher drain current and more rapid turn-off characteristics are evident as the temperature is decreased. However, HSPICE ring oscillator simulations based on measured I-V results (Figure 2) suggest only minimal circuit level performance improvement. Delay improvements are especially poor at lower power supply voltages, which will be the desired operating point at low temperatures to avoid enhanced hotcarrier degradation [3] and to ease required cooling power.

The lack of improvement in the room temperature designed devices at low temperature is caused by an increase in threshold voltage, which limits the improvement in current (Figure 3). In addition, carrier freezeout of the p-channel threshold implant leads to an even larger increase in the PMOS threshold voltage and poorer subthreshold slope improvement. The NMOS and PMOS LDD regions also freezeout and cause an increase in the parasitic source/drain resistances at lower temperature (Figure 4), further limiting the current. 


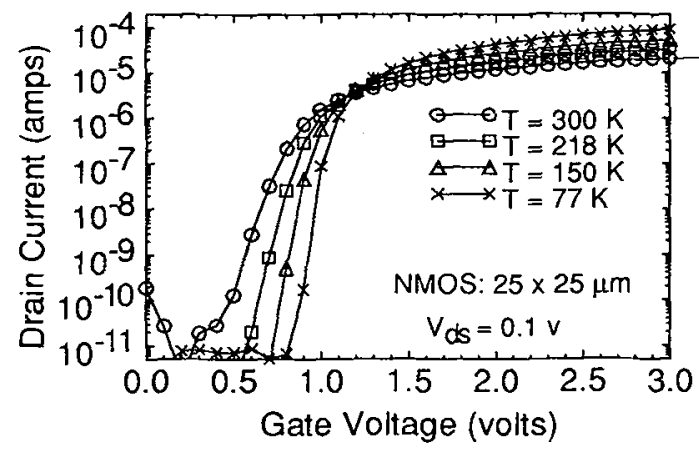

Figure 1: $\mathrm{I}_{\mathrm{ds}}-\mathrm{V}_{\mathrm{gg}}$ curves (log scale) for a $25 \times 25 \mu \mathrm{m}$ NMOS device at $300 \mathrm{~K}, 218 \mathrm{~K}, 150 \mathrm{~K}$, and $77 \mathrm{~K}$.

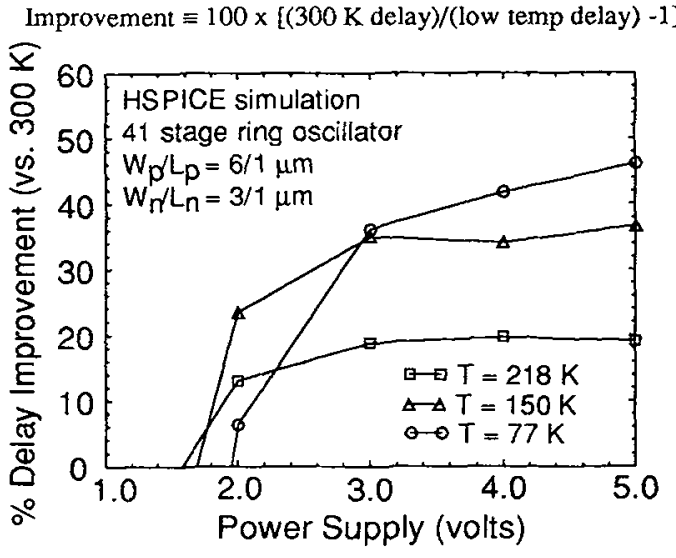

Figure 2: Improvement in delay versus power supply voltage for temperatures of $218 \mathrm{~K}, 150 \mathrm{~K}, 77 \mathrm{~K}$. Data is normalized to the propagation delay of a 41 stage ring oscillator at $300 \mathrm{~K}$. At best, only a $1.5 x$ delay reduction is achievable. $(77 \mathrm{~K}, 5 \mathrm{v})$

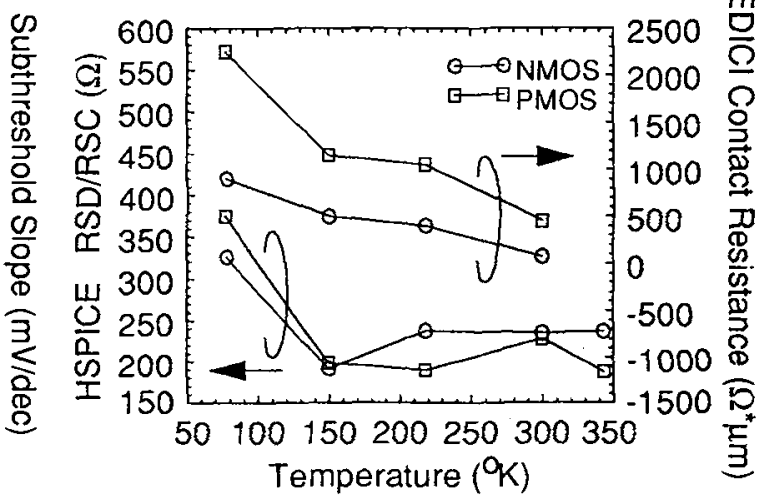

Figure 3: Threshold voltage and subthreshold slope versus temperature for $25 \times 1 \mu \mathrm{m}$ devices. A constant $250 \mathrm{nA}$ current is used to define $V_{\text {th. }}$.
Figure 4: Parasitic source/drain resistances used in HSPICE and MEDICI programs to fit the measured data at $300 \mathrm{~K}$, $218 \mathrm{~K}, 150 \mathrm{~K}$, and $77 \mathrm{~K}$. The increase in resistance at lower temperatures is due to LDD freezeout.

\section{DESIGN APPROACH FOR LOW TEMPERATURE CMOS}

A series of TCAD tools were used to examine the effects of process modification on low temperature performance (Figure 5). Starting with the baseline room temperature process flow, process changes are first run through SUPREM to obtain a new doping profile. MEDICI [4] then imports the profile, producing I-V curves. Improvement on the device level can be obtained by comparing these new I-V curves with the original results. To measure circuit level improvement, an extraction and fit to HSPICE should be performed. 


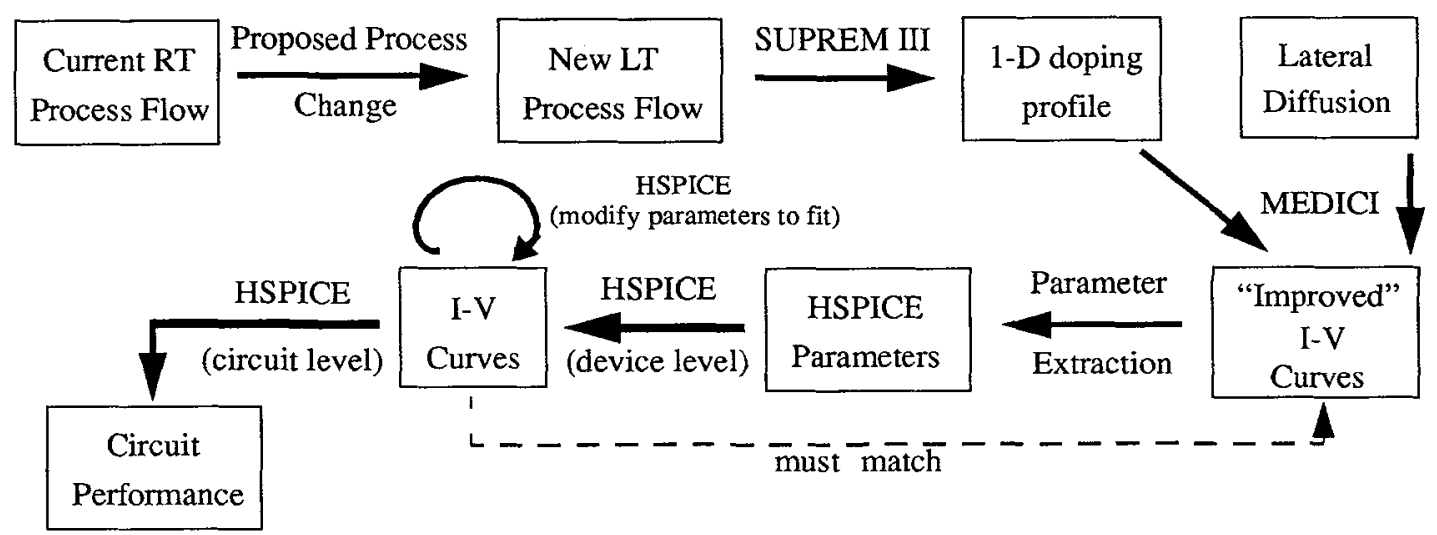

Figure 5: Illustration of how process (SUPREM), device (MEDICI), and circuit (HSPICE) simulation tools are used together to improve the performance of low temperature CMOS. Input decks identical to those used to fit the original, measured results (except for the doping profile) are used as a starting point.

\section{THRESHOLD VOLTAGE ADJUSTMENT}

\subsection{To Room Temperature Value}

Using the above technique, the threshold voltage implants were modified to decrease the high threshold voltage at low temperature. Figure 6 shows the implant doses needed to obtain the same room temperature threshold voltage. A larger increase in the PMOS threshold implant dose is necessary to counter freezeout effects. However, the changes are not large enough to worsen short channel effects. The effect of the threshold adjustments on the device level is shown in Figure 7 for a $25 \times 1 \mu \mathrm{m}$ NMOS transistor. Although the linear current only improves slightly, performance on the circuit level is greatly enhanced. Figure 8 shows HSPICE ring oscillator delays for the original and threshold adjusted cases. The amount of improvement is larger at lower temperatures due to the greater shift in threshold voltage.

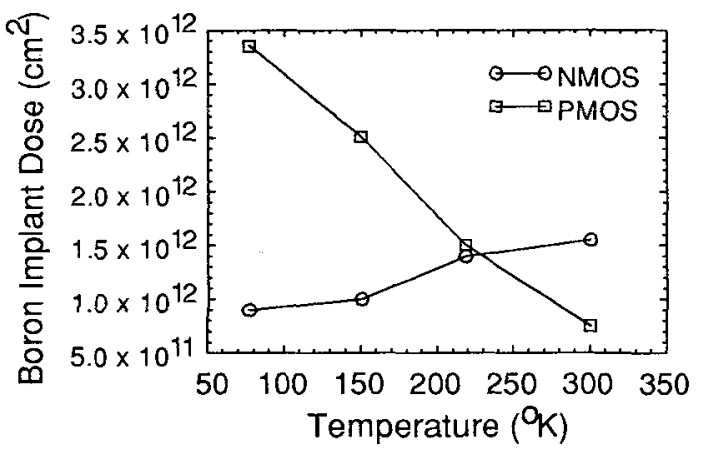

Figure 6: Threshold adjustment implant doses (boron) necessary to maintain a $300 \mathrm{~K}$ threshold voltage for a given operating temperature.

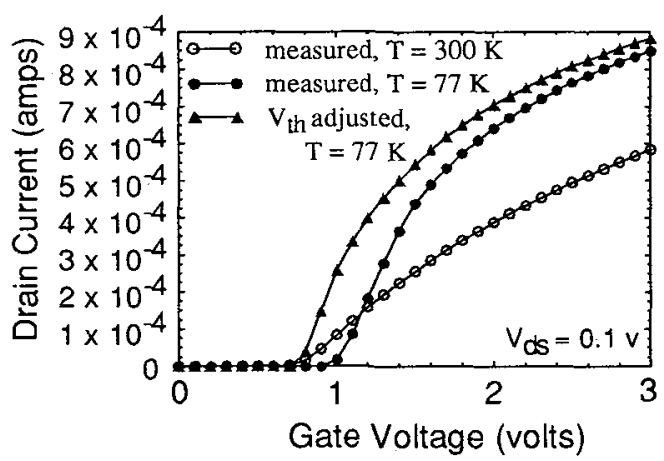

Figure 7: Improvement in the linear drain current characteristics of a $25 \times 1 \mu \mathrm{m}$ NMOS device at $77 \mathrm{~K}$ as a result of threshold adjustment. A better match with the $300 \mathrm{~K}$ threshold voltage is evident. Freezeout in the LDD regions limit the improvement in current. 
Improvement $\equiv 100 \times[(300 \mathrm{~K}$ delay $) /($ low temp delay $)-1]$

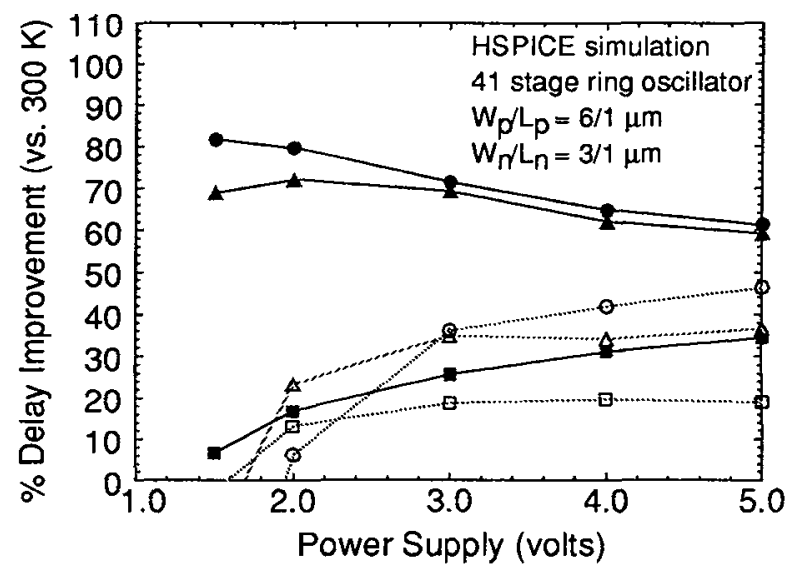

Legend:

$\because T=218 \mathrm{~K}, V_{\text {th }}$ Adjusted

$\rightarrow T=150 \mathrm{~K}, V_{\text {th }}$ Adjusted

$\because T=77 \mathrm{~K}, V_{\text {th }}$ Adjusted

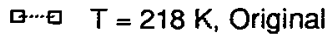

$\Delta \cdots \Delta \quad T=150 \mathrm{~K}$, Original

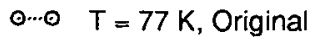

Figure 8: Improvement in ring oscillator delay (normalized to $300 \mathrm{~K}$ results) versus power supply voltage as a result of threshold implant adjustment. Delays at $218 \mathrm{~K}, 150 \mathrm{~K}$, and $77 \mathrm{~K}$ were simulated. Original results are also shown for comparison.

Freezeout of the LDD regions minimizes the improvement between $150 \mathrm{~K}$ and $77 \mathrm{~K}$. Changing the LDD implant to reduce the high parasitic resistance and increase reliability $[5,6]$ will further improve the $77 \mathrm{~K}$ performance.

\subsection{Below Room Temperature Value}

Due to the improvement in subthreshold slope at lower temperatures, a lower than room temperature threshold voltage can be used without causing additional off-state leakage. Figure 9 shows the amount of performance enhancement possible at $77 \mathrm{~K}$ with a "25\% lower than room temperature" threshold voltage. The improvement is more significant for lower power supply voltages, which will be the

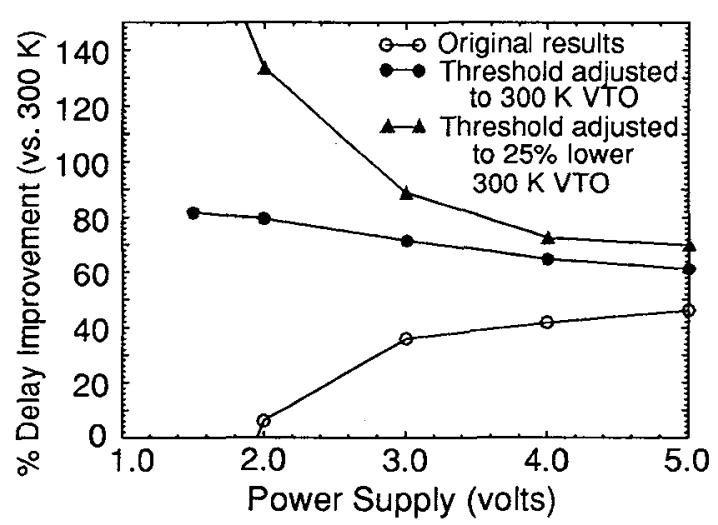

Figure 9: Improvement in delay at $77 \mathrm{~K}$ versus power supply voltage for a lower than room temperature threshold voltage. Delay improvements based on the original, measured results and threshold adjustment to a room temperature threshold voltage are shown for reference. A $2 x$ improvement in delay at low power supply $(2.8 \mathrm{v})$ is now possible.

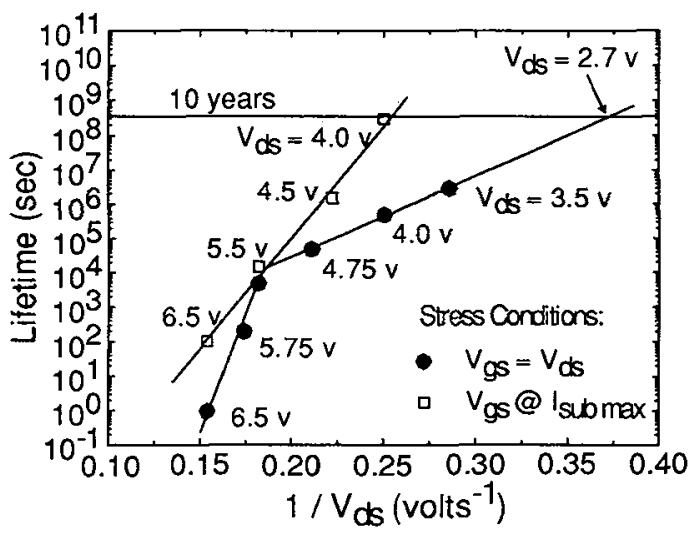

Fi gure 10: Lifetime versus $1 /$ (drain bias) for $25 \times 1 \mu \mathrm{m}$ NMOS devices at $77 \mathrm{~K}$. A $10 \%$ degradation in maximum transconductance $\left(\mathrm{g}_{\mathrm{m}}\right)$ is used to define device lifetime. Two different stress conditions are used: $V_{g s}$ corresponding to maximum substrate current (worst case degradation at $300 \mathrm{~K}$ ) and $\mathrm{V}_{\mathrm{gs}}=\mathrm{V}_{\mathrm{ds}}$ (worst case at $77 \mathrm{~K}$ ). 
desired operating voltage as suggested by the lifetime data (Figure 10). The threshold voltage can be further lowered to gain even more improvement. However, other issues such as testability at room temperature and maximum off-state current need to be considered.

\section{CONCLUSION}

By simply adjusting the threshold voltage implants for a room temperature technology, significant performance improvements at low temperature are possible. Additional process changes can be made to further improve low temperature performance, such as redesigning the $\mathrm{LDD}$, using $\mathrm{P}^{+}$polysilicon for the PMOS gate (to prevent channel doping freezeout), and adding a retrograded well. However, the cost of implementing these more complex processes needs to be considered and carefully examined.

\section{References}

[1] K. Kakumu, D. Peters, H. Liu, and K. Chiu, "Design Optimization for Deep-Submicron CMOS Device at Low Temperature Operation", IEDM, December 1990, p. 211-214.

[2] J. Koga, et. al., IEEE Trans. on Elec. Dev., ED.41 (1994), p. 1179-1183.

[3] M. Song, K. MacWilliams, J. Cable, and J. Woo, "Bias and Temperature Dependence of Hot Carrier Lifetime from $77 \mathrm{~K}$ to $300 \mathrm{~K}$ ", IEDM, December 1992, p. 707-710.

[4] TMA MEDICI: Two-Dimensional Device Simulation Program (ver. 1.1.3), Technology Modeling Associates, Inc.

[5] M. Song, J. Cable, J. Woo, and K. MacWilliams, IEEE Elec. Dev. Let., EDL-12 (1991), p. $375-$ 377.

[6] I. Groves, et. al., "One-Micrometer, Radiation-Hardened Complementary Metal Oxide Semiconductor for Cryogenic Analog Applications", Infrared Readout Electronics II, Proceedings of SPIE: The International Society for Optical Engineering, Volume 2226, April 1994, pages 72-84. 